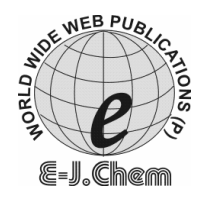

\title{
Estimation of Atenolol by Reverse Phase High Performance Liquid Chromatography
}

\author{
NAVEEN KUMAR*, NISHANT VERMA, OMVEER SONGH, \\ NAVEEN JOSHI and KANWAR GAURAV SINGH ${ }^{\S}$.
}

School of Pharmaceutical Sciences, Shobhit University, Meerut-250110, India.

${ }^{\S}$ Singhania University Pacheri Bari, Distt. Jhunjhunu (Rajasthan)-333515, India.

kaushiknave@gmail.com

Received 6 December 2009; Accepted 2 February 2010

\begin{abstract}
A simple, precise, sensitive, fast and accurate high performance liquid chromatography method has been developed for the determination of atenolol using mixture of phosphate buffer and acetonitrile (53:47 v/v) as mobile phase. Buffer was prepared by mixing $0.02 \mathrm{M} \mathrm{K}_{2} \mathrm{PO}_{4}$ and $0.003 \mathrm{M} \mathrm{KH}_{2} \mathrm{PO}_{4}$ in equal proportion. Detection was carried out using UV detector at $\lambda_{\max } 230 \mathrm{~nm}$. Column was ODS and dimensions of column was $25 \mathrm{~mm} \times 4.6 \mathrm{~mm}$. Atenolol was eluted out at retention time of $2.1 \mathrm{~min}$. Method was validated at $1.2 \mathrm{~mL} / \mathrm{min}$ flow rate. Calibration curve was linear between ranges of 40 to $200 \mathrm{mcg}$ concentration. The limit of detection was calculates 120 nano gram and limit of quantitation is 510 nano gram. The relative standard deviation (RSD) of atenolol was 0.6 . The percentage recovery of atenolol was $99.6 \%$.
\end{abstract}

Keywords: HPLC, ODS, Validation, Atenolol.

\section{Introduction}

HPLC is high performance liquid chromatography. It can be used for qualitative and quantitative analysis. HPLC is very sophisticated instrument and widely used in analysis ${ }^{1-4}$. Atenolol is well known drug widely used in the treatment of hypertension. Atenolol (ATL), chemically is known as $(R, S)$-4-(2-hydroxy-3-isopropyl-aminopropoxy) phenyl acetamide, is a beta-adrenoceptor antagonist. It is official in the Indian Pharmacopoeia ${ }^{4-6}$ and the British Pharmacopoeia. Literature reveals that there are few methods for estimation of atenolol in bulk and its dosage form. Several works have been reported on atenolol determination in plasma, formulations adopting gas chromatographic techniques with an electron capture detector or HPLC, using reverse phase columns and UV or fluorometric detection $^{6-10}$. These methods can be used successfully for quality control testing of the drugs from single and combined dosage form. 


\section{Experimental}

Standard bulk drug sample of atenolol is procured from Unicare (India) Pvt. Ltd., Noida (U.P.) India. All other reagents used were of analytical grade for spectroscopic method and HPLC grade for HPLC method.

HPLC is schimadzu SPD 10 a modal system with $1 \mathrm{~cm}$ matched quartz cell was used for spectrophotometric method. Spectra were recorded using specific program of apparatus, having specifications as follows: Spectral bandwidth $3 \mathrm{~nm}$, wavelength accuracy $\pm 0.5 \mathrm{~nm}$ and wavelength readability $0.1 \mathrm{~nm}$ increments. Acetonitrile is HPLC grade from Rankem which is already passed through 0.2 micron pore size filter paper. Water is triple distilled that used in this experiment and passed through 0.45 micron filter paper with help of vacuum pump. $\mathrm{K}_{2} \mathrm{HPO}_{4}$ and $\mathrm{KH}_{2} \mathrm{PO}_{4}$ were also GR grade which used in HPLC analysis and they are both from Rankem. All the glass wares are made up of borosilicate glass.

\section{Chromatographic conditions}

Chromatographic separations were achieved using an Inertsil ODS $\mathrm{C}_{18}(250 \times 4.6 \mathrm{~mm}, 5 \mu)$ analytical column. The mobile phase consisting of acetonitrile and phosphate buffer $(47: 53 \mathrm{v} / \mathrm{v})$ was passed through $0.45 \mu$ membrane filter and degas by altrasonications. The flow rate was maintained at $1.2 \mathrm{~mL} / \mathrm{min}$ and the measurements were made at $230 \mathrm{~nm}$. The column and the HPLC system were kept in ambient temperature

\section{Preparation of buffer solution}

Phosphate buffer $\mathrm{pH} 7$ was prepared by dissolving $136 \mathrm{mg}$ of potassium dihydrogen phosphate in $100 \mathrm{~mL}$ of water and $0.52 \mathrm{mg}$ of dipotassium hydrozen phosphate in $100 \mathrm{~mL}$ of water. The above solutions are mixed in 1:1 ratio to get $\mathrm{pH} 7$.

\section{Preparation of mobile phase}

Prepared buffer and acetonitrile were mixed in 53:47 (v/v) ratios. The solution was sonicated to degas mixture. Mobile phase was passed through $0.45 \mu \mathrm{m}$ pore size filter paper.

\section{Standard solution}

Atenolol standard solution was prepared by separately dissolving $25 \mathrm{mg}$ of pure drug in $25 \mathrm{~mL}$ of mobile phase. Standard atenolol was dissolved in $15 \mathrm{~mL}$ of mobile phase and sonicated for $5 \mathrm{~min}$. Then diluted to $25 \mathrm{~mL}$ with mobile phase to get $100 \mu \mathrm{g} \mathrm{mL}^{-1}$ for atenolol and passed through $0.45 \mu \mathrm{m}$ membrane filter. Mixture was degas by altrasonications. At first, a blank solution (mobile phase) was injected and chromatogram was recorded. Before injection of these solutions into injector loop, it passed through $0.45 \mu \mathrm{m}$ filter. Chromatogram of atenolol was recorded as given in Figure 1.

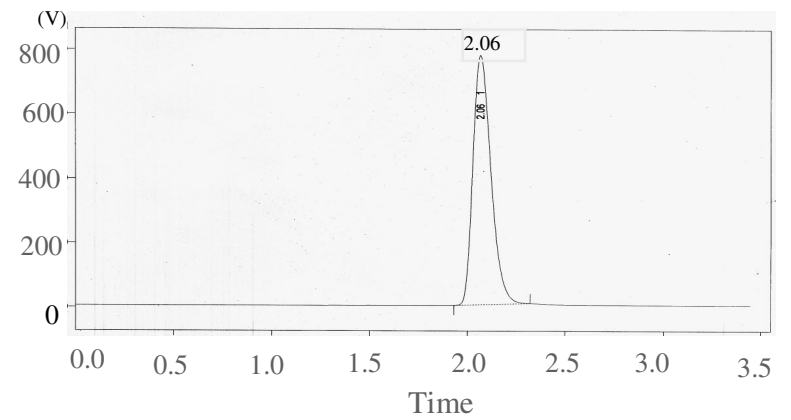

Figure 1. Typical chromatogram of standard atenolol. 


\section{Method validation ${ }^{11-13}$}

Linearity and range of method was determined on standard solution by analyzing 40 to $200 \mathrm{mcg} / \mathrm{mL}$ concentration of test concentration and the calibration curve was plotted using AUC versus concentration of standard solution (Figure 2). Accuracy of method was ascertained by recovery study by adding a known amount of standard drug ( $\pm 20 \%$ of test concentration) to pre-analysed sample and reanalyzing the samples by the proposed method. Precision was studied by analyzing six replicates of standard solution. Specificity was carried out by injecting placebo solution. The chromatographic parameters were also validated by system suitability studies (Table 1) which were carried out on freshly prepared standard stock solution.

Table 1. System suitability.

\begin{tabular}{ccc}
\hline S. No. & Parameters & Obtained values \\
\hline 1 & Retention time, min & 2.096 \\
2 & Area & 2072.2 \\
3 & S.D & 7.5 \\
4 & RSD & 0.3 \\
\hline
\end{tabular}

\section{Results and Discussion}

\section{Linerity}

A linear relationship should be evaluated across the range of the analytical procedure. It is be demonstrated directly on the substance (by the dilution of standard stock solution) and separate weighing of synthetic mixture of the product component, using the proposed procedure. The latter aspect can be studied during investigation of range.

Linearity should be evaluated by the visual inspection of a plot of signals as a function of compound concentration content. If there is a linear relationship, test results should be evaluated by appropiate statistical methods, for example- calculation of a regression line by the method of least square. In some cases, to obtain linearity between assay and sample concentration, the test data need to be subjected to a mathematical transformation prior to regression analysis. Data from the regression line itself may be helpful to provide mathematical estimates of the degree of linearity.

Calibration curves were constructed using three series of standard atenolol solution in the range of $40.0-200.0 \mu \mathrm{g} / \mathrm{mL}$. The equation of linear regression and statistical data are presented in Figure 2. The linearity of the calibration curve was validated by the high value of the correlation coefficient. They were represented by the linear regression equation

$$
\mathrm{Y}_{\mathrm{AT}}=652.44 \mathrm{X}+95.726 \text { and } \mathrm{R}^{2}=0.9996 \text {. }
$$

\section{Precison}

Intra day precison was performed for six replicate for drug in method under the limit of ICH guideline. Relative standard deviation of atenolol is 0.64 . The assays gave satisfactory results; the relative standard deviations (RSD.) were less than 2. This level of precision of the proposed method was adequate for the quality control analysis of atenolol in its pharmaceutical formulations.

\section{Accuracy test}

The accuracy of the method was checked by recovery study using standard addition method at three different concentration levels, i.e., multilevel recovery study. The preanalyzed samples were spiked with extra 80,100 and $120 \%$ of the standard atenolol and the mixtures 
were analyzed by proposed method. Recovery of standard drugs added was found to be $98.3-101 \%$ with the value of \%RSD less than 1.0 indicating that the proposed method was accurate. Results of recovery study are shown in Table 2.

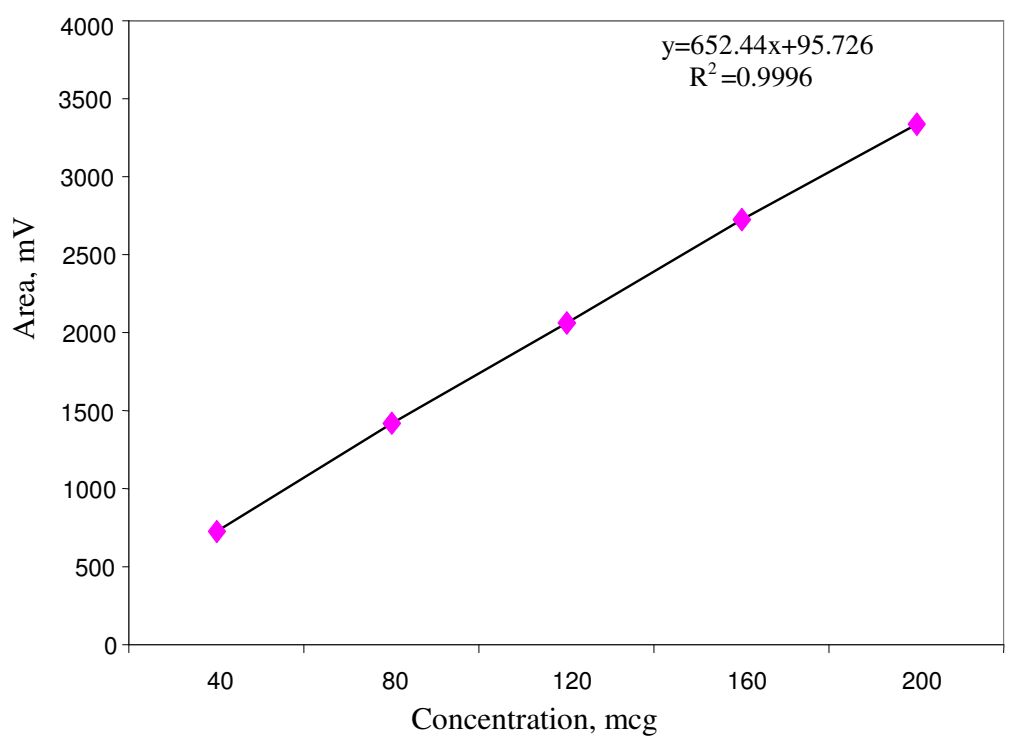

Figure 2. Linearity graph of atenolol.

Table 2. Recovery data for the proposed RP-HPLC method ( $n=3)$.

\begin{tabular}{cccccc}
\hline S. No. & $\begin{array}{c}\text { Concentration } \\
\text { added, } \\
\mathrm{mcg} / \mathrm{mL}\end{array}$ & $\begin{array}{c}\text { Recovered, } \\
\mathrm{mg}\end{array}$ & $\begin{array}{c}\% \\
\text { Recovered }\end{array}$ & Mean & RSD \\
\hline 1 & 80 & 81.1 & 101.3 & 101.3 & 0.38 \\
2 & 80 & 80.8 & 101 & & \\
3 & 80 & 81.3 & 101.6 & & \\
\hline 4 & 100 & 100.2 & 100 & & \\
5 & 100 & 99.9 & 100 & 100 & 0.35 \\
6 & 100 & 99.7 & 100 & & \\
\hline 7 & 120 & 118.2 & 98.3 & & \\
8 & 120 & 118.2 & 98.5 & 98.5 & 0.16 \\
9 & 120 & 118.5 & 98.7 & & \\
\hline
\end{tabular}

\section{Conclusion}

Reversed phase method was developed for estimation of atenolol. The developed method was accurate, precise, sensitive and fast and could estimate atenolol. The developed method is economic and efficient as compared to other methods. This method could be utilized in quantitative analysis of drugs in pharmaceutical formulations. Atenolol was taken for the study. The drug eluted successfully at specific times. Chromatogram of the drug showed good peak shape and resolution. Developed method was validated. Validation indicated the potential of developed method. The developed method proved its suitability as it could successfully analyzed the drug in marketed products and this can be used for routine analysis of two drugs. 


\section{References}

1. Gajewska M, Glass G and Koste ecki J, Acta Pol Pharm., 1992, 49(3), 1-4.

2. Keech A C, Harrison P M and Mclean A J, J Chrom Biomed Appl., 1988, 70, 234-236.

3. Rao G R, Avadhanulu A B, Giridhar R, Pantalu R R and Kokate C K, East Pharm., 1990, 33(386), 125-126.

4. Shimoka K, Sawada Y and Teternatsu H, J Pharm Biomed Anal., 1989, 7(11), 1267-1272.

5. Indian Pharmacopoeia, Indian Pharmacopoeia Commission, 1996, 1, 73-75.

6. Arias R, Jim R M, Alonso R M, Lez M T, Arrieta I, Flores P and Lastra E O, $J$ Chromatogr A, 2001, 916, 297-304.

7. Carl A G, The Comprehensive Pharmacology Reference, 2008, 1-6.

8. Johnell K and Fastbom J, Arch Osteoporos, 2009, 4(1-2), 17-23.

9. Agon P, Goethals P, Van Haver, D and Kaufman J M, J Pharm Pharmacol., 1991, 43, 597-600.

10. $\quad$ Krzesinski J M and Scheen A J, Rev Med Liege., 2009. 64(2), 103-108.

11. Knight C J and Fox K M, Am J Cardiol., 1998, 81(2), 133-136.

12. Lindgren P, Buxton M, Kahan T, Poulter N R, Dahlöf B, Sever P S, Wedel H and Jönsson B, Pharmacoeconomic, 2009, 27(3), 221-23.

13. Yamanaka S, Tatsumi T, Shiraishi J, Mano A, Keira N, Matoba S, Asayama J, Fushiki S, Fliss H and Nakagawa M, J Am Coll Cardiol., 2003, 41(5), 870-878. 


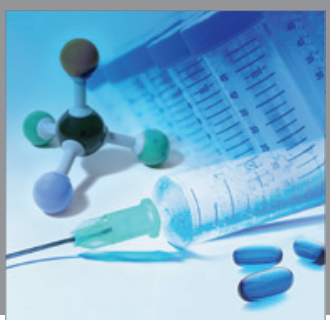

International Journal of

Medicinal Chemistry

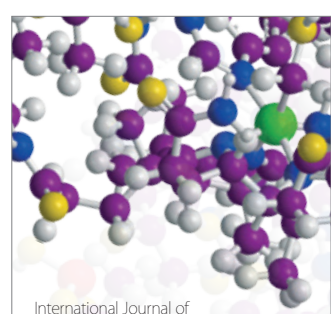

Carbohydrate Chemistry

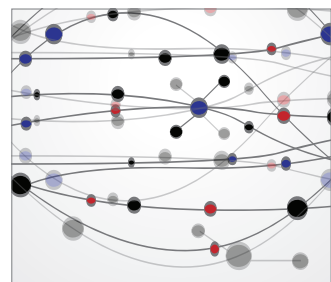

The Scientific World Journal
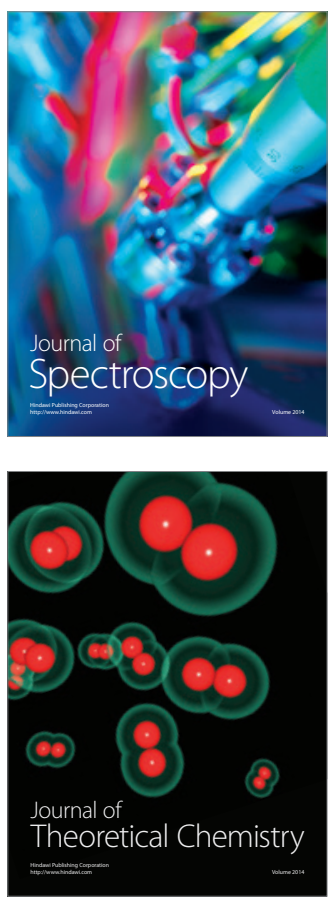
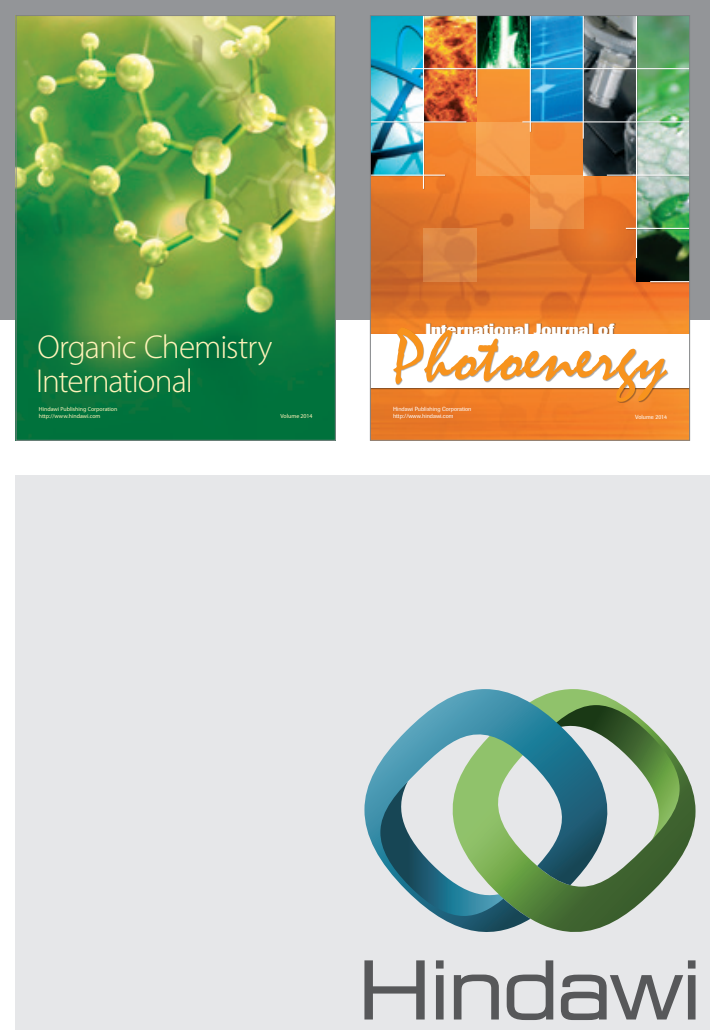

Submit your manuscripts at

http://www.hindawi.com
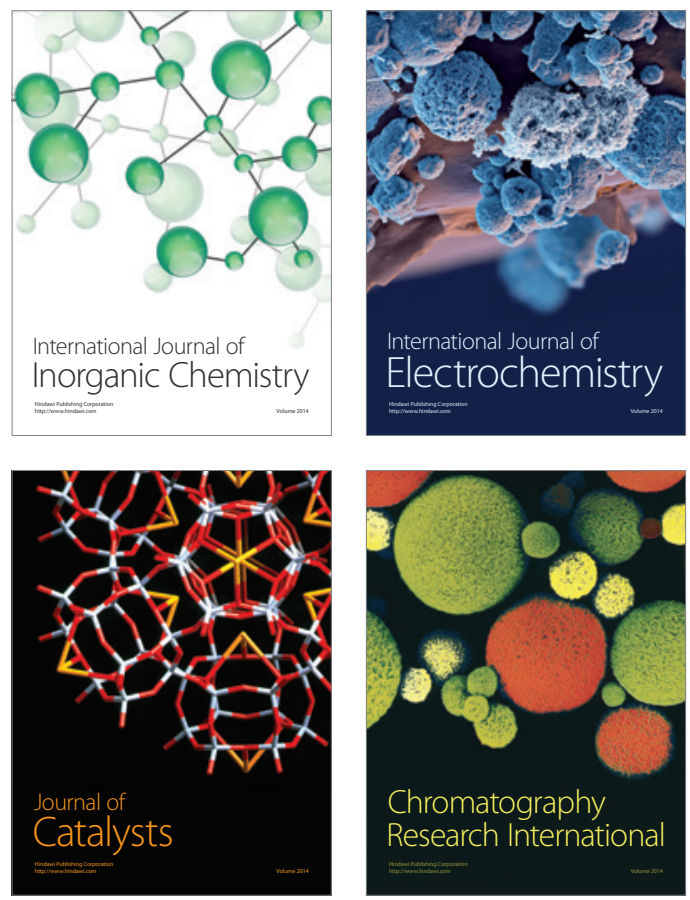
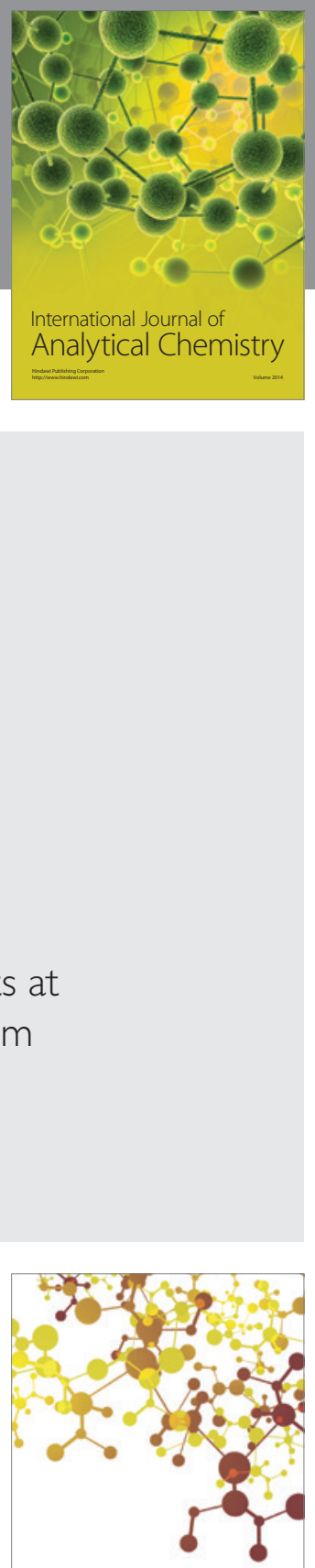

Journal of

Applied Chemistry
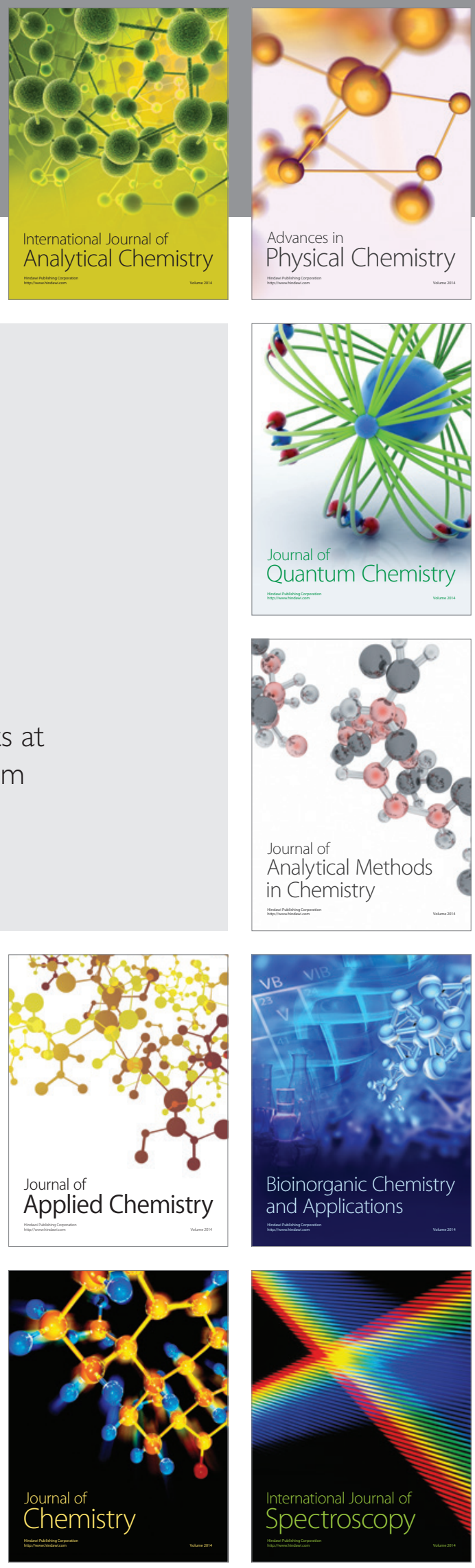